Journal of Science $\quad$ Gazi University

\title{
Feasibility of Offshore Wind Energy in Turkey; A Case Study for Gulf of Edremit at the Aegean Sea
}

\author{
Muammer OZBEK ${ }^{1, *}$ (D) Kerim Mehmet Murat TUNC ${ }^{2}$ (D) \\ ${ }^{I}$ Istanbul Bilgi University, Faculty of Engineering and Natural Sciences, Department of Civil Engineering, 34060, Istanbul, Turkey \\ ${ }^{2}$ Istanbul Bilgi University, Faculty of Engineering and Natural Sciences, Department of Energy Systems Engineering, 34060, Istanbul, Turkey
}

\author{
Highlights

\begin{tabular}{l} 
Article Info \\
\hline \\
Received: 09 May 2020 \\
Accepted: 07 Sep 2020 \\
Keywords \\
\hline Wind energy \\
Offshore wind turbine \\
Cluster/farm design \\
Fluid mechanics \\
Dynamic interactions
\end{tabular}

- Feasibility analyses were performed for a 50-90 MW offshore wind farm.

- Farm layout is determined by considering wind speed and sea depth data.

- Energy yield and capacity factors were computed for 8 different turbines.

\begin{abstract}
This work aims to investigate the feasibility of offshore wind energy in Turkey by performing extensive simulations and analyses for a 50-90 MW capacity offshore wind park to be constructed at the Gulf of Edremit, a very high potential site located at the Aegean Sea, $3 \mathrm{~km}$ from the west coastline of Turkey. The location and layout of the farm is optimized by considering the sea depth data obtained from bathymetric maps and wind speed measurements acquired from the MERRA data and local met mast. Dynamic interactions among the turbines and the resulting wake losses are modeled by using two different site assessment programs. Capacity factors and the annual energy production yields are calculated for 8 different types of turbines with rated powers changing between 2 and $3.6 \mathrm{MW}$.
\end{abstract}

\section{INTRODUCTION}

Global energy demand is continuously increasing due to growing world population and rapid industrialization seen in developing countries. Since fossil fuels have irreversible negative effects on environment and are definitely bound to run out, many countries have been seeking for renewable energy sources. Among currently existing alternatives, wind energy, which is based on a well-established and mature technology, can be considered as the fastest growing and the most promising source. Indeed, wind power has received considerable attention worldwide and reached a capacity of $650 \mathrm{GW}$ at the end of 2019 , $5.4 \%$ of the global energy supply [1].

Over the last few decades, wind industry has been focusing on onshore wind power to fulfil the increasing demand in a time and cost efficient way. Today, the installed wind power capacity is mainly (622 GW) located on shore. However, these and possible future onshore installations are restricted by several factors such as land availability and public opposition due to noise problems and visual impact on the environment.

Unfortunately, most of the available onshore areas in Europe have been in use for this purpose. In some cases for the sites which are close to residential areas, some public objection can be made by local communities due to noise and visual nuisance. As a consequence, governments have started imposing several restrictions on the projects to minimize the impact on environment and on inhabitants living nearby the proposed wind farms [2]. 
For onshore wind farm construction, terrain complexity is an important issue that constrains the investor by increasing the cost of the infrastructure required for the project. Terrains with limited accessibility and road restrictions can be quite tough for transportation and installation of large wind turbines.

Complex terrains also require advanced air flow modeling and turbulence analyses to be performed not only to maximize the annual energy production but also to minimize the aerodynamic loads which can reduce the service life of the turbine significantly.

Despite the technical difficulties encountered in construction and maintenance of marine structures, offshore wind power is expected to be a common solution to these problems. Indeed, compared to onshore based projects, installations at sea have some significant advantages [2]. The winds on sea are always stronger and more stable than the winds on land, enabling the turbines to operate with higher capacity factors. Since air flow characteristics are much easier to simulate, the annual energy yield and the resulting income can be estimated more accurately reducing the financial risks which the investors have to face with.

As all the construction takes place on sea, the size and capacity of the turbines are not limited by visual concerns or the availability of the existing transportation facilities. In addition, since coastal areas are generally economical and industrial centers with high energy demand, producing the electricity close to the regions where it will be consumed the most, definitely reduces the transmission loss and cost $[3,4]$.

The existing problems and drawbacks related to offshore wind energy such as high installation costs and technical difficulties encountered in operation and maintenance of the farms are expected to be solved by using more advanced construction techniques and maintenance strategies. More detailed information related to the current state of offshore wind energy applications can be reached through some recent articles [3-7]. Indeed, considering the fact that offshore wind power will be essential for achieving national renewable energy targets, many countries have been conducting extensive research programs and feasibility studies to determine their offshore wind power capacities and to develop new technologies which will enable this unlimited source to be exploited in a more efficient manner [7-13].

\section{WIND ENERGY IN TURKEY}

In this work, the feasibility of offshore wind energy in Turkey is discussed by presenting the results of the analyses performed for the Gulf of Edremit, a region which is determined to have high wind energy potential. Turkey, as a rapidly growing economy with a population of 82 million (2018) has very limited national hydrocarbon resources. Below, Figure 1 shows how the total installed power capacity is distributed among several energy sources in 2019 [14]. Despite the significant hydro-electric power (32\%) capacity, approximately $40 \%$ of the total consumption is still dependent on the coal, natural gas and fuel imported for electricity production. Depending on the yearly fluctuations encountered in renewable energy sources, the foreign dependency can be as high as $50 \%$.

The heavy economic burden of importing these resources and more importantly, the increasing awareness of environmental issues have been encouraging policy makers to increase the use of renewable energy sources [14]. Indeed, very detailed analyses were conducted to determine the renewable energy capacity of the country [15-20]. Within the scope of a long term project, a very important contribution to estimate the national wind power capacity was made in 2007 by the preparation of REPA database (REPA is the Turkish abbreviation for the Atlas for Wind Energy Potential of Turkey). 


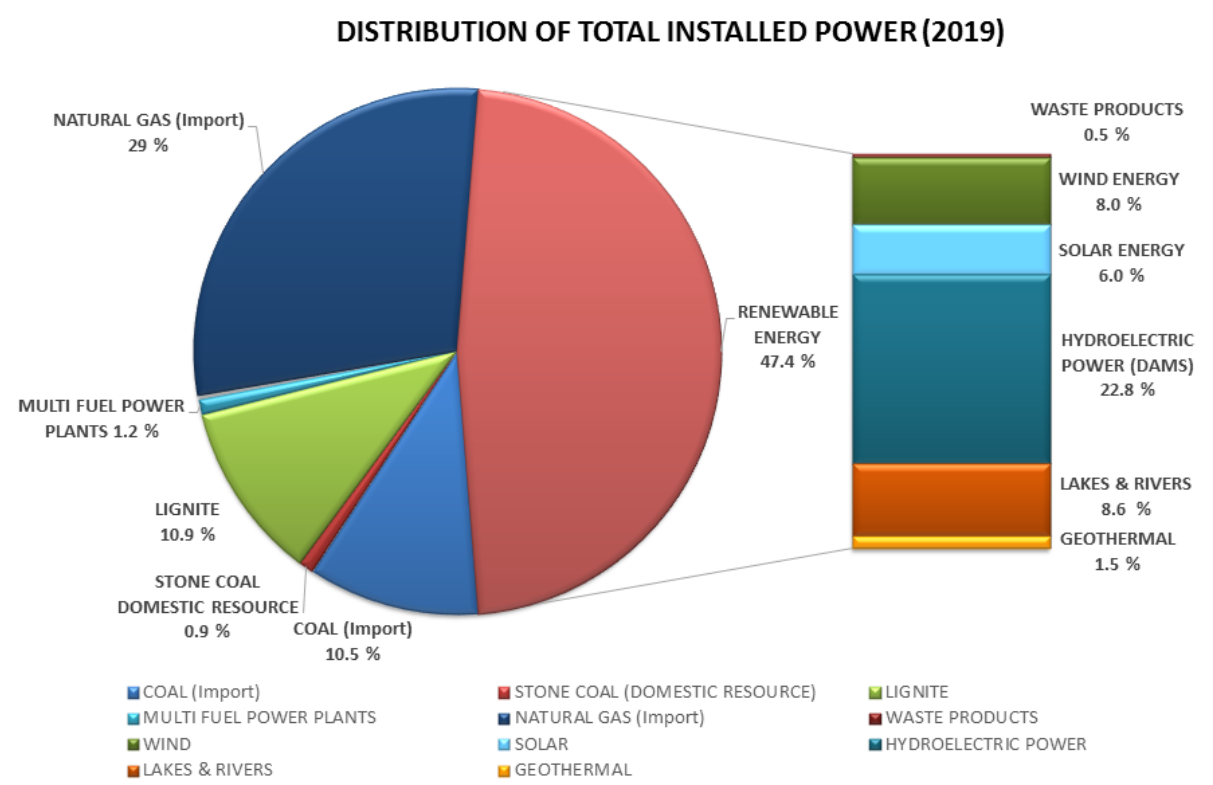

Figure 1. The distribution of total installed power (in 2019) among different sources [14]

The renewable energy program initiated in 2007 enabled the total installed wind power capacity to increase from $146 \mathrm{MW}$ in 2007 to 8,056 MW in 2019 [14]. Below, Figure 2 shows the yearly change of installed wind power capacity. It is planned to increase the capacity to 20,000 MW in 2030. Despite this significant progress, the total capacity is limited to onshore wind turbine installations only. Although Turkey is surrounded by sea on three sides and has a coastline of $8,300 \mathrm{~km}$, currently there is no offshore wind farm in Turkey. Since marine construction projects require more complicated techniques to be used and therefore, have higher initial investment costs, onshore wind energy alone was considered to be a time and cost efficient solution to reach the short term plans and projections.

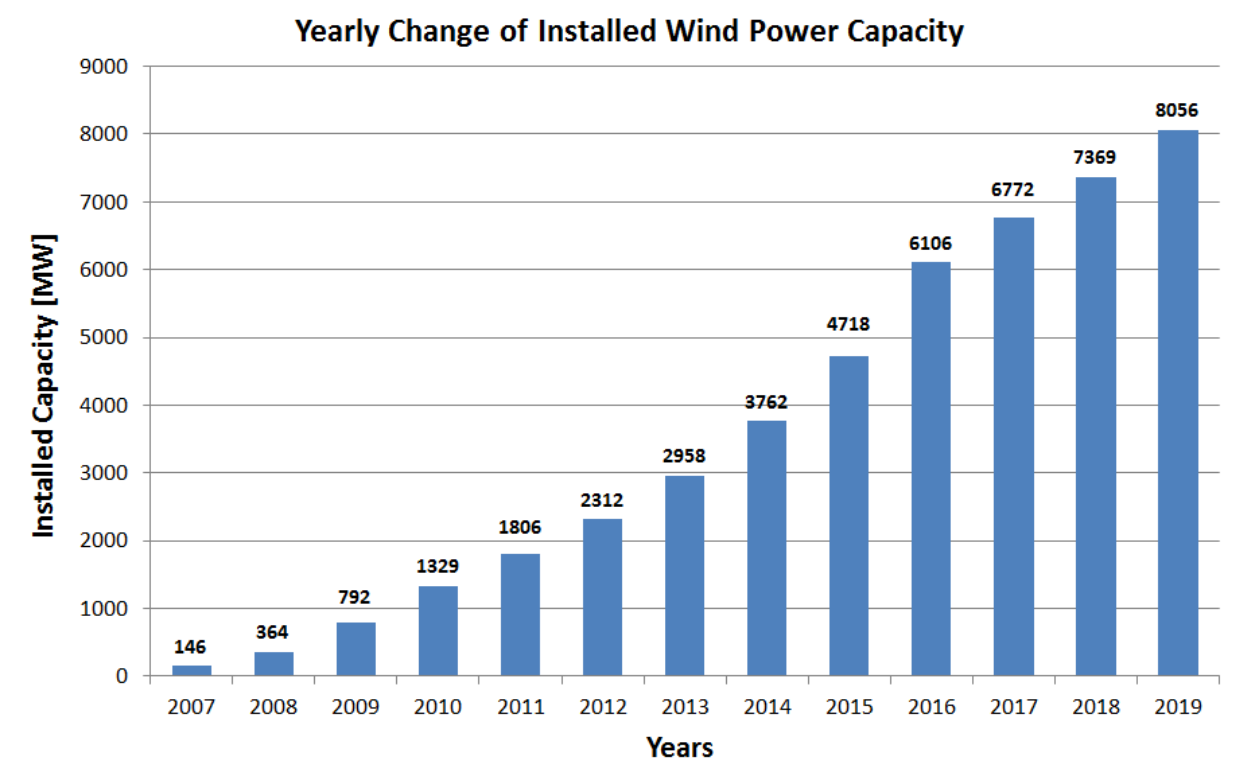

Figure 2. Yearly increase in total installed wind power between 2007 and 2019 in Turkey [14]

Following the experience gained during onshore applications and the encouraging decrease in the cost of offshore turbine installations, several offshore wind farm projects are expected to be developed to exploit the wind energy potential of the country in a more efficient way. This work aims at conducting a feasibility study for one of the high potential sites which can be used for this purpose. 


\section{THE LOCATION OF THE WIND FARM}

Site assessment analyses presented in this work were conducted by using the data acquired from REPA wind energy atlas [21]. A typical example of wind speed distribution maps given in REPA can be seen in Figure 3 below. The map shown in the figure shows the wind speed distribution calculated for an altitude of 100 meters. The site, Edremit Gulf, is located at the Aegean Sea, $3 \mathrm{~km}$ from the west coastline of Turkey. It is surrounded by Kaz Mountains on the north, Lesbos island on the west and Cunda island on the south. The length of the gulf is $80 \mathrm{~km}$ in east-west direction. The width changes between 10 and $50 \mathrm{~km}$ in northsouth direction. The location of the gulf is shown by the black circle in Figure 3. The site proposed for the farm is displayed in more detail in Figure 4.

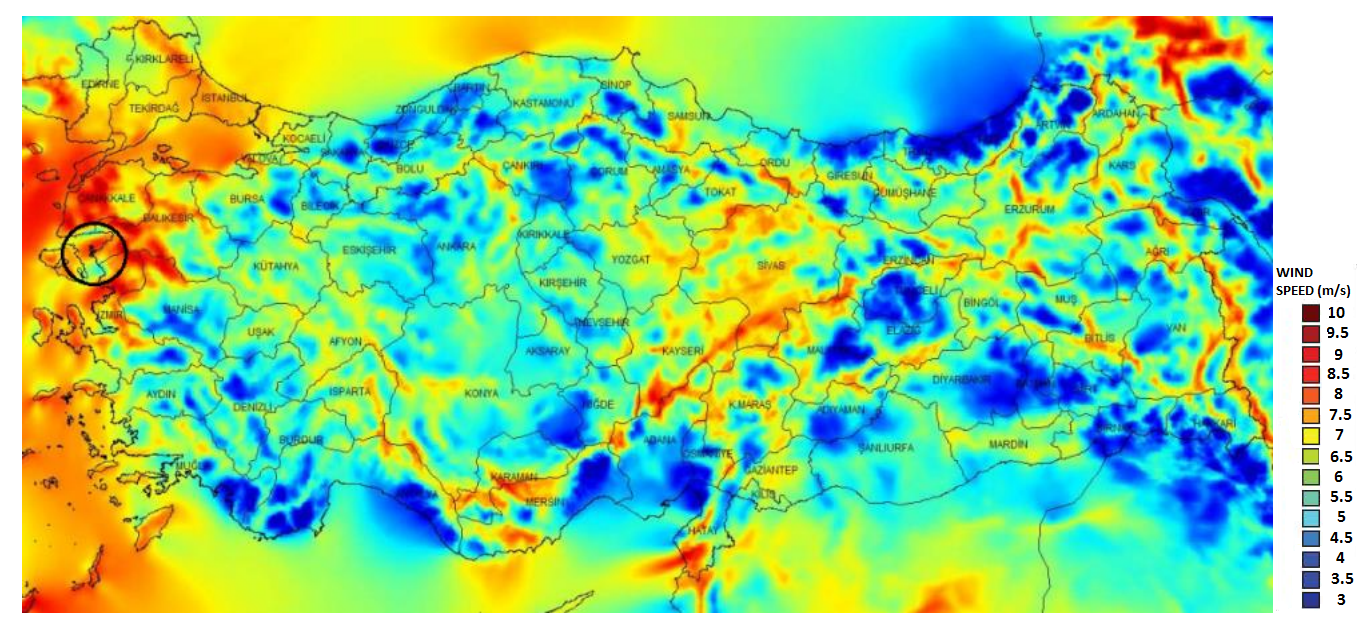

Figure 3. REPA Wind speed distribution at an altitude of $100 \mathrm{~m}$ [21]

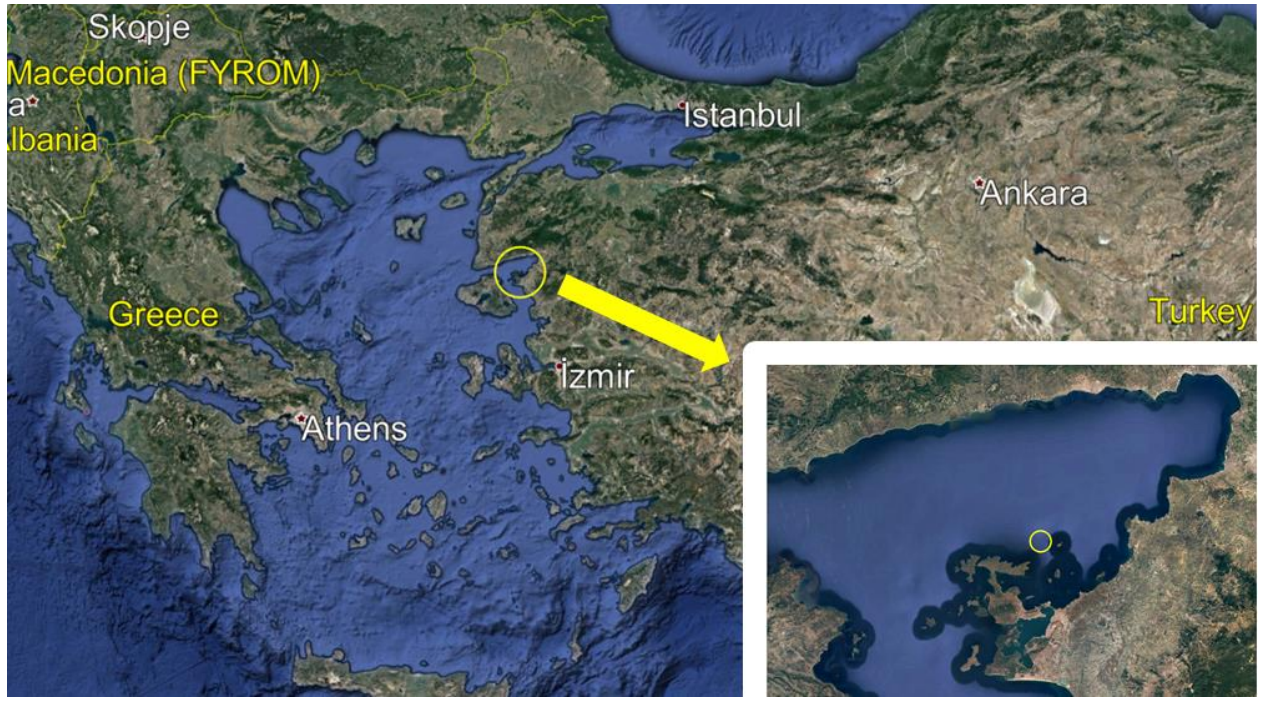

Figure 4. The location of the farm [22]

Similarly, based on the data acquired from REPA [21], the areas on which wind farms can be constructed are shown in more detail in Figure 5. The figure shows the available areas for both onshore and offshore installations. Several factors such as topography, terrain slope, sea depth bathymetric data (for offshore wind farms), existing transportation facilities and transmission network, earthquake faults, bird migration routes are taken into account in evaluating site availability and the unsuitable areas are shown in gray and black color. The average wind speed data for the available sites is also represented by using the color-scale given in the figure. The location of the offshore wind farm proposed in this work is shown by the black circle. 


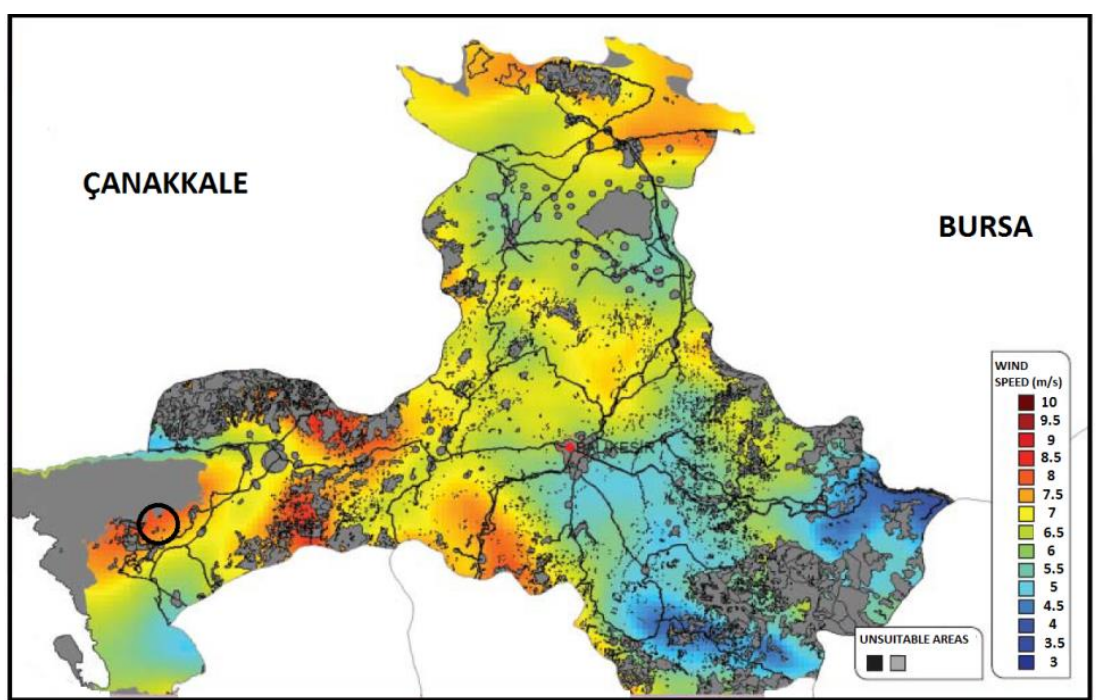

Figure 5. Available wind farm locations and corresponding average wind speed [21]

In addition to topographical and physical constraints, the current infrastructure is also considered to determine the feasibility of wind energy for a given site. The existing power transmission network and the locations of active substations which are already in use can be seen in Figure 6 below. As can be seen in the figure, since the proposed farm (shown by the black circle) is very close to an onshore substation, the generated electricity can easily be regulated and then transmitted to the existing system without requiring any additional modifications in the present grid network.

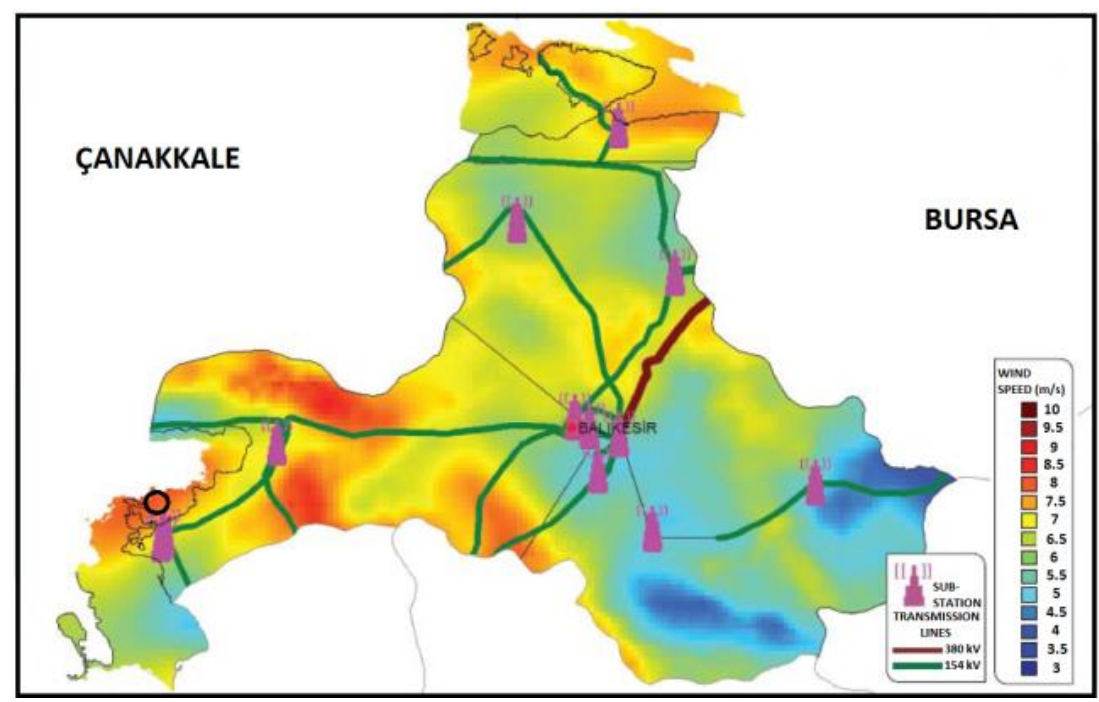

Figure 6. Existing Substations and power transmission lines [21]

Within the scope of the work, sea depth data for the selected area was acquired from GEBCO (General Bathymetric Chart of the Oceans) Bathymetry maps [23], an example of which can also be seen in Figure 7. The regions with a sea depth up to 30 meters were considered to be appropriate for the turbine construction. 


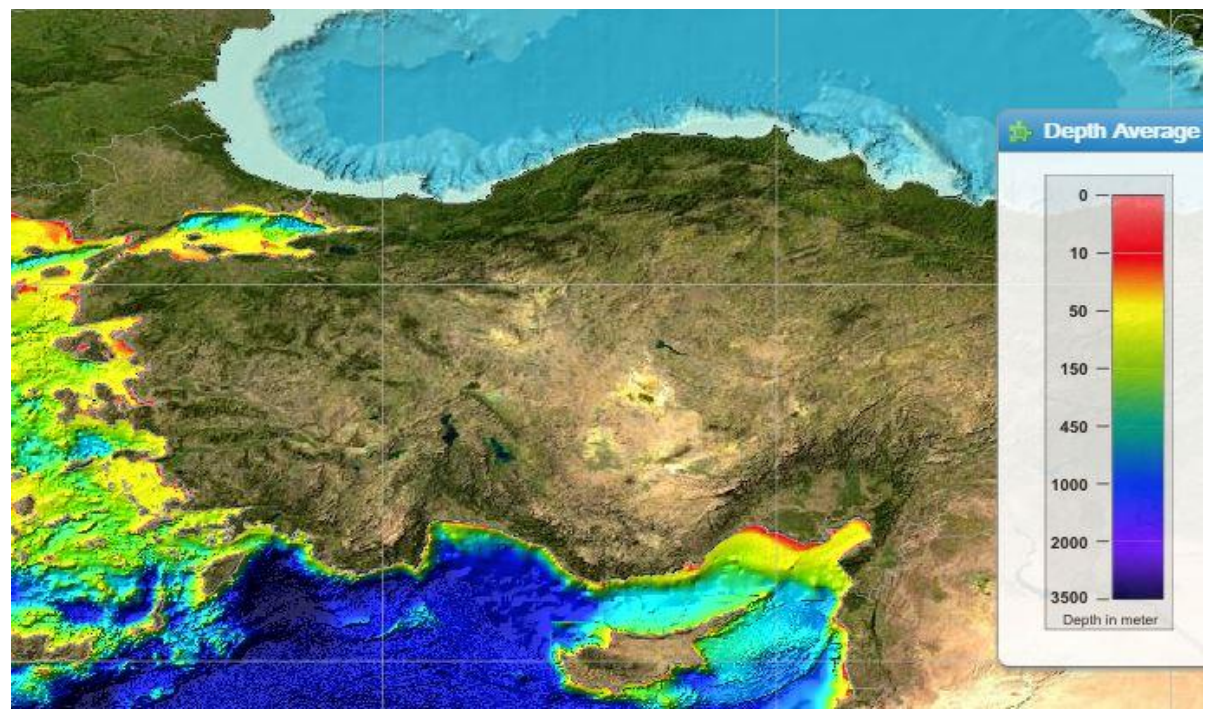

Figure 7. GEBCO Bathymetry map of the Turkey, [23]

\section{DATA ANALYSIS AND METHODOLOGY}

The analyses presented in this work were performed by using two different site assessment programs (WAsP and FUGA) developed by Technical University of Denmark. WAsP [24-27] is linearized production estimation software and can be used for both onshore and offshore energy yield simulations. Similarly, FUGA [28] is a linearized CFD (Computational Fluid Dynamics) modeling tool to study offshore wind farm wakes and to provide annual energy yield. Within the scope of the project, flow modeling has been done by WAsP Engineering tool. The extreme wind occurrence and turbulence intensity of the site has been calculated by using MERRA (Modern-Era Retrospective Analysis for Research and Applications) data [29] which represents a time period of 29 years between 1985 and 2014.

Site specific (e.g. wind speed measurements, terrain information, and farm layout) and turbine specific properties (e.g. power curves) are the key input data to be used for the site assessment analysis. The energy produced at a given wind speed is calculated by multiplying the power generated at this speed by the total duration of the period during which the analyzed wind speed is observed. In order to estimate the annual energy production, this procedure is repeated for different wind speeds and the obtained energy yields are added as shown in Equation (1)

$$
E=T \int_{V_{c i}}^{V_{c o}} P(u) F(u) d u
$$

In Equation (1), $T$ represents the total number of hours per year. $F(u)$ and $P(u)$ are the frequency of the occurrence of the wind with speed of $u$ and the corresponding power generated at this wind speed, respectively. The limits of the integral $V_{C i}$ and $V_{C o}$ stand for the cut-in and cut-out wind speeds. A turbine starts rotating when the wind speed is greater than or equal to cut-in speed (3-4 m/sec) and produces electricity until cut-out limit is reached $(25 \mathrm{~m} / \mathrm{sec})$. When cut-out value is exceeded, the turbine stops rotating, pitches its blades out of the wind and switches to safety mode in order to survive under extreme load conditions.

In Equation (1), discrete wind speed measurements are converted to a continuous function by using Weibull distribution. For this purpose, first the frequency distribution of the obtained wind speed data set is modeled by statistical Weibull distribution function which is described by Equation (2) shown below 


$$
F(u)=\frac{k_{w}}{A_{w}}\left(\frac{u}{A_{w}}\right)^{\left(k_{w}-1\right)} \exp \left[-\left(\frac{u}{A_{w}}\right)^{k}\right]
$$

In Equation (2), A and $\mathrm{k}$ values are the scale and the shape parameters which define the magnitude and the skewness of the given data series. In this work, scale and shape parameters of the analyzed data are calculated by WAsP by using the moment fitting method. For more detailed information readers are referred to [25-26]. By using these parameters, mean wind speed $(\bar{U})$ and mean power density $(\bar{E})$ can be calculated by using Equation (3) and Equation (4) as follows;

$$
\begin{aligned}
& \bar{U}=A_{w} \Gamma\left(1+\frac{1}{k_{w}}\right) \\
& \bar{E}=\frac{1}{2} \rho A_{w}^{3} \Gamma\left(1+\frac{3}{k_{w}}\right)
\end{aligned}
$$

In the equations shown above, $\rho$ and $\Gamma$ represent the air density and gamma function, respectively. The abovementioned methodology which is applied to calculate the annual energy production (AEP) is also briefly summarized below in Figure 8 (a-c).

In Figure 8a, discrete wind speed measurements are displayed by blue colored bar chart. These discrete measurements are then converted to a continuous frequency function by using Weibull distribution which is represented by the red curve. Power curve, a turbine specific feature which describes the power generated by the turbine at different wind speeds, is shown in Figure $8 \mathrm{~b}$. As can be seen in the figure, power generation starts when wind speed is higher than $3 \mathrm{~m} / \mathrm{sec}$ and reaches at its maximum value when the speed is approximately $12 \mathrm{~m} / \mathrm{sec}$ (rated wind speed). When the speed is higher than $25 \mathrm{~m} / \mathrm{sec}$ the turbine stops rotating and switches to safety mode.
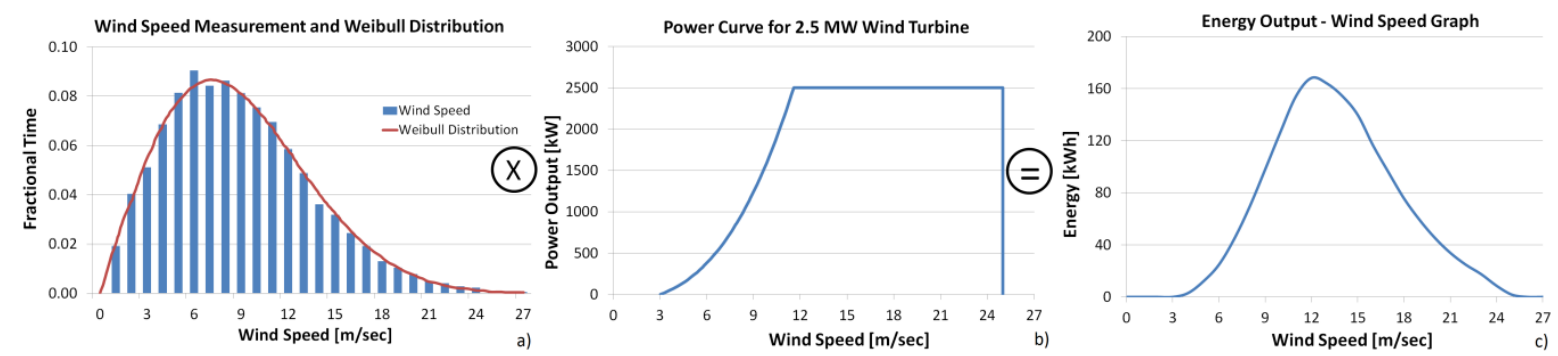

Figure 8. Calculation of AEP (Annual Energy Production), a) Wind Speed Measurements and Weibull Distribution b) Power Curve for a 2.5 MW wind turbine c) Energy Output vs. wind speed

Figure 8c shows how energy generation changes as a function of wind speed. It is the resultant of turbine specific and site specific properties and acquired by multiplying Weibull Distribution and power curve. The annual energy production is the sum of yields obtained for different wind speeds. It corresponds to the total area under the graph or in other words, the integral described in Equation (1). As can be seen in the figure, for wind speeds lower than cut-in or higher than cut-out limits there is no power generation.

\section{WIND SPEED MEASUREMENTS}

The wind speed data used for the analyses has been provided from local meteorological station where the speed was measured at two different tower heights of $10 \mathrm{~m}$ and $30 \mathrm{~m}$, respectively. Then the measurements have been correlated by the MERRA data [29] which represents a time period of 29 years between 1985 and 2014. The Weibull distribution and the wind roses of these three data sets (met mast 10m, met mast $30 \mathrm{~m}$ and MERRA 50m) are presented in Figure 9 below. As can be seen from the figure, the prevailing 
wind direction is between 30-60 degrees. In this direction, there is Mount Ida with an altitude of 1200m. The dominant wind direction is coming from land to the sea.

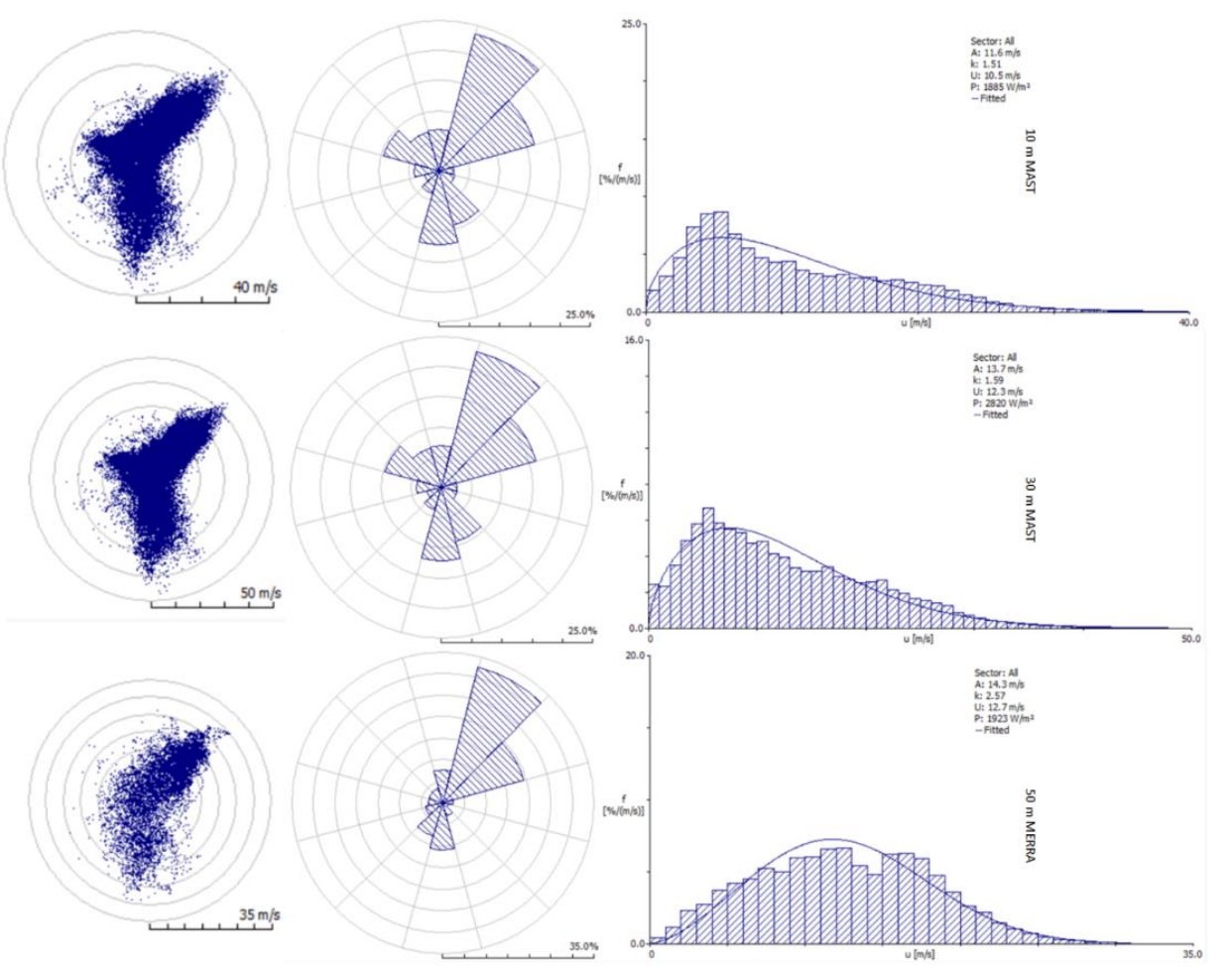

Figure 9. The Weibull fit and the wind roses of the 10m, 30m and MERRA $50 \mathrm{~m}$ data

\section{DESIGN OF THE FARM LAYOUT}

For energy yield calculations, power curves were acquired for 8 different commercially available wind turbine models having capacities between $2 \mathrm{MW}$ and 3.6 MW. In order not to promote a wind turbine model or manufacturer specifically, the names of these turbines were not given explicitly in the article. Instead, the analyzed turbine models were identified by a number only (e.g. T1-T8). Similarly, all turbines were assumed to have monopile foundation which can be applied at locations where the maximum sea depth is 30 meters.

Since the area with a maximum sea depth of $30 \mathrm{~m}$ is limited, the number of turbines, their locations and capacities should be optimized by extensive analyses. In order to minimize wake losses and turbulence effects, the distance between the turbines is recommended to be 4-6 times the rotor diameter. The farm layout proposed in this work can be seen in Figure 10. The farm is planned to have 25 turbines placed as 3 rows in the dominant wind direction. As a site specific design parameter, average wind speed distribution can also be seen in the figure.

The interactions among the turbines and the resulting wake propagation were also simulated by using FUGA, linearized CFD modeling tool. Figure 11 below shows the wake effects at a certain cross-section within the farm simulated for a certain wind speed and direction. The figure shows the wake distribution acting on the turbines in the $3^{\text {rd }}$ row in the vertical $\mathrm{X}-\mathrm{Z}$ plane where $\mathrm{Z}$ is the altitude measured from the sea level. 


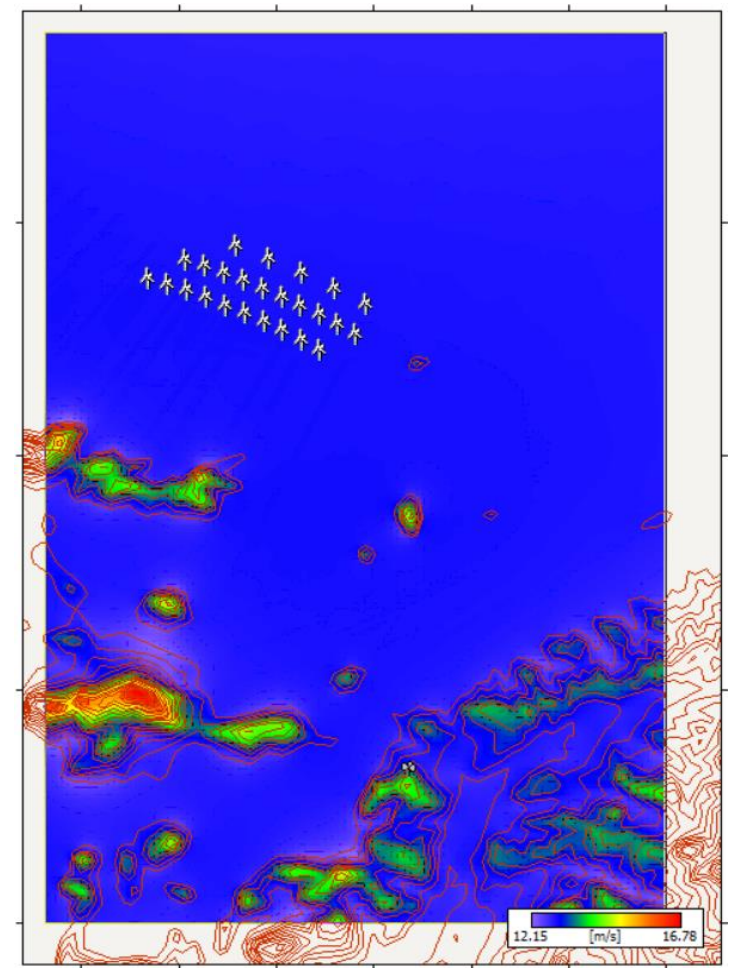

Figure 10. Mean wind speed distribution over the calculated grid

In Figure 11, horizontal axis represents the distance normalized by the rotor diameter. The vertical-axis on the right shows the height measured from sea level. The wind speed at the hub $(\mathrm{z}=90 \mathrm{~m}) \mathrm{can}$ be seen on the left axis. The yellow plot shows how the upwind wind speed changes due to the wake created by the previous turbines in the $2^{\text {nd }}$ row. For the points away from the wakes wind speed is undisturbed and equal to $10 \mathrm{~m} / \mathrm{s}$. It should be noted that the wind is in y direction which is perpendicular to the $\mathrm{X}-\mathrm{Z}$ plane described in the figure.

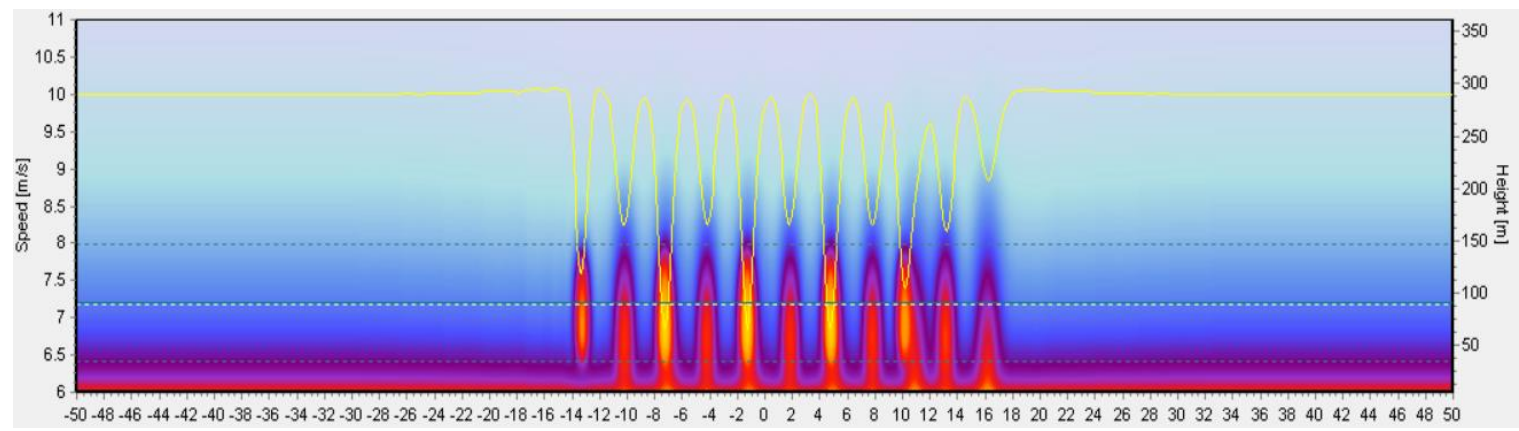

Figure 11. Wake effects within the farm (FUGA simulation, front view X-Z Plane)

\section{EXTREME WIND SPEED CALCULATION}

Extreme wind speed was predicted by using met mast measurements taken at 30 meters and MERRA data which cover a long term period of 30 years. The corresponding calculations were performed by using Gumbel's method [30] which is based on the extreme wind speeds observed at a certain location for time duration of ten years or more. The parameters required to derive the Gumbel's cumulative distribution function can be obtained by fitting a regression line to the recorded extreme speed measurements.

Below Figure 12a shows the values and the dominant directions of the recorded extreme wind speeds. As can be seen, the strongest winds always blow in northeast-southwest direction. These extreme wind speed values are used to find the Gumbel's distribution function which is shown in Figure 12b. The calculated distribution function can then be used to estimate extreme wind speeds that are expected to be observed for 
a certain time period. As shown in the figure, the extreme wind speed is estimated as $19.4 \mathrm{~m} / \mathrm{s}$ within a period of 50 years. The values have a uniform distribution and a non-steep slope.
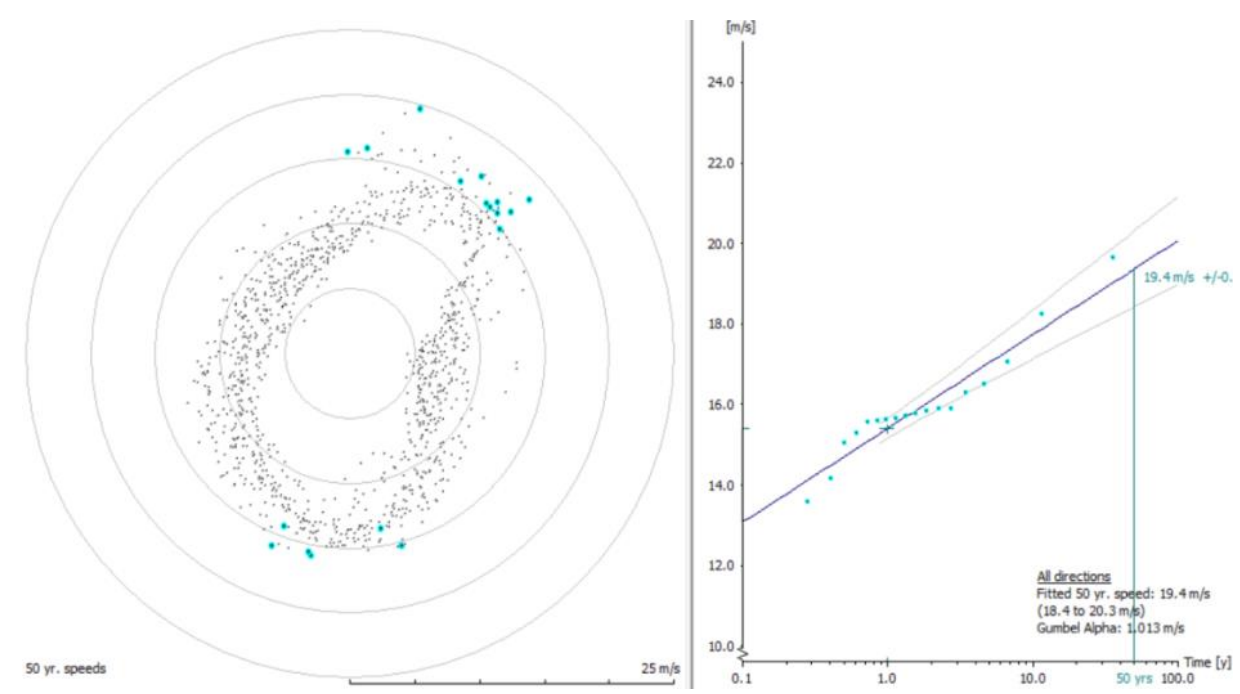

Figure 12. Extreme wind speed calculation a) distribution of extreme wind speeds with respect to direction b) Gumbel's distribution function

\section{ANNUAL YIELD AND CAPACITY FACTOR RESULTS}

Annual energy yields and the corresponding capacity factors calculated for 8 different turbines by using WASP and FUGA are summarized in Tables 1 and 2, respectively. The analyses are performed by using two different tools to be able to benefit from specific advantages of each method.

FUGA is specialized for offshore wind farm analyses. Some physical constraints, for example, the temperature effects on the density or the vertical motion of air while rising from the heated surface would be different on land and on sea. Thus, FUGA is expected to be more reliable for offshore applications. As it is a wake model which assumes a horizontally homogeneous atmospheric boundary layer, it is mainly optimized for a flat terrain with a constant roughness length. Therefore, the effects of complex terrain and topography may not be represented with high accuracy.

Since offshore wind farms are usually located far from the shore, change in airflow characteristics due to terrain conditions is usually not very critical. Except from the wake effects and turbulence generated by the turbines themselves, some important parameters such as dominant wind direction and speed are usually the same for very large areas.

Table 1. Annual energy yield and capacity factors calculated by WAsP

\begin{tabular}{|c|c|c|c|c|c|c|}
\hline \multirow{2}{*}{ Turbine } & \multirow{2}{*}{$\begin{array}{c}\text { Rated Power } \\
{[\mathrm{MW}]}\end{array}$} & $\begin{array}{c}\text { Capacity } \\
{[\mathrm{MW}]}\end{array}$ & $\begin{array}{c}\text { AEP } \\
{[\mathrm{GWh}}\end{array}$ & $\begin{array}{c}\mathrm{AEP}_{\text {Net }} \\
{[\mathrm{GWh}]}\end{array}$ & $\begin{array}{c}\text { Wake } \\
\text { Loss [\%] }\end{array}$ & Cap. Factor \\
\hline T1 & 3 & 75 & 309 & 296 & 4.1 & 0.45 \\
\hline T2 & 2.5 & 63 & 253 & 244 & 3.5 & 0.44 \\
\hline T3 & 3 & 75 & 310 & 296 & 4.3 & 0.45 \\
\hline T4 & 3.6 & 90 & 369 & 349 & 5.3 & 0.44 \\
\hline T5 & 2 & 50 & 199 & 194 & 2.9 & 0.44 \\
\hline T6 & 3 & 75 & 294 & 284 & 3.3 & 0.43 \\
\hline T7 & 3 & 75 & 310 & 297 & 4.2 & 0.45 \\
\hline T8 & 3.3 & 83 & 345 & 329 & 4.4 & 0.45 \\
\hline
\end{tabular}


WAsP is widely used for onshore applications where airflow is affected by not only the other turbines in the farm but also the surrounding topography significantly. As shown in Figure 10, the proposed wind farm is not located very far from the shore $(3 \mathrm{~km})$ and therefore, the terrain conditions may still have effects on the observed airflow characteristics. Since WAsP can take into account the topographical effects more accurately, it is expected to be more advantageous in analyzing the sites which have more complex geometries and layouts. On the other hand, sea surface is considered just as a flat surface with very low roughness. The special features of offshore applications such as temperature and humidity may not be represented very accurately. Hence, comparing the results obtained from two different tools is expected to provide a better insight in evaluating the capacity of this challenging site.

Table 2. Annual energy yield and capacity factors calculated by FUGA

\begin{tabular}{|c|c|c|c|c|c|c|}
\hline \multirow{2}{*}{ Turbine } & \multirow{2}{*}{$\begin{array}{c}\text { Rated Power } \\
{[\mathrm{MW}]}\end{array}$} & $\begin{array}{c}\text { Capacity } \\
{[\mathrm{MW}]}\end{array}$ & $\begin{array}{c}\text { AEP } \\
{[\mathrm{GWh}]}\end{array}$ & $\begin{array}{c}\mathrm{AEP}_{\text {Net }} \\
{[\mathrm{GWh}]}\end{array}$ & $\begin{array}{c}\text { Wake } \\
\text { Loss [\%] }]\end{array}$ & Cap. Factor \\
\hline T1 & 3 & 75 & 313 & 302 & 3.5 & 0.46 \\
\hline T2 & 2.5 & 63 & 256 & 249 & 2.7 & 0.45 \\
\hline T3 & 3 & 75 & 312 & 301 & 3.5 & 0.46 \\
\hline T4 & 3.6 & 90 & 371 & 356 & 4 & 0.45 \\
\hline T5 & 2 & 50 & 199 & 194 & 2.3 & 0.44 \\
\hline T6 & 3 & 75 & 298 & 290 & 2.4 & 0.44 \\
\hline T7 & 3 & 75 & 311 & 300 & 3.4 & 0.46 \\
\hline T8 & 3.3 & 83 & 342 & 329 & 3.6 & 0.45 \\
\hline
\end{tabular}

As can be seen in the tables, there are only very small differences between the results obtained from two different site assessment tools. The wake losses calculated by WAsP are always slightly greater than the losses predicted by FUGA. Wake losses get higher as the size or the capacity of the turbine increases. For larger rotor diameters, wind speed profile definitely needs a longer distance to recover the turbulence effects and deficit in speed. Therefore, the distance between the turbines is proportional to the size of the blade and generally recommended to be 4-6 times the rotor diameter.

Depending on the type of the selected wind turbine, the calculated capacity factors change between $43 \%$ and $46 \%$ which can be considered as quite high and promising. Below Table 3 presents the capacity factors (C.F.) calculated for major operational offshore wind parks in some European countries [31]. In the table the active wind farms are ordered with respect to their total installed capacity. For simplicity only the farms with an installed capacity of $100 \mathrm{MW}$ or greater are included in the list. As can be seen in Table 3, the capacity factors change significantly between $29 \%$ and $53 \%$. However, only 3 out of 46 farms have a capacity factor which is greater than or equal to $50 \%$. By considering the total installed power it can be concluded that the weighted average of the capacity factors summarized below is $41 \%$.

The capacity of a wind farm can be determined by aiming at maximizing either the total installed power capacity or the efficiency. Since the capacity factors (efficiencies) predicted for different models are very close, it is recommended to use a high capacity turbine (T4 $3.6 \mathrm{MW})$ to maximize the energy production. Therefore, the analyzed region is considered to be very appropriate for the construction of a wind farm with 25 turbines and a total capacity of $90 \mathrm{MW}$. The capacity factor which is the average of the values obtained from WAsP and FUGA is $44.5 \%$.

As can be seen, the total capacity of the offshore wind farms listed in Table 3 is $14,670 \mathrm{MW}$. Similarly, the total capacity of the farms having capacity factors greater than or equal to $44.5 \%$ is $4,691 \mathrm{MW}$ or in other words $32 \%$ of the total installed power. Therefore, it can be concluded that the proposed wind farm will be more efficient than remaining $68 \%$ of the major wind farms located in European Countries. 
Table 3. Capacity factors (C.F.) calculated for some offshore wind parks in Europe

\begin{tabular}{|l|c|c|c|}
\hline Wind Farm & Country & $\begin{array}{c}\text { Capacity } \\
\text { (MW) }\end{array}$ & C.F. \\
\hline Walney 3 \& 4 & UK & 659 & 49 \\
\hline London Array & UK & 630 & 39 \\
\hline Beatrice & UK & 588 & 49 \\
\hline Gwynt-y-Mor & UK & 576 & 34 \\
\hline Race Bank & UK & 573 & 42 \\
\hline Greater Gabbard & UK & 504 & 41 \\
\hline Hohe See & DE & 497 & 42 \\
\hline B. Riffgrund II & DE & 450 & 31 \\
\hline Dudgeon & UK & 402 & 48 \\
\hline Rampion & UK & 400 & 29 \\
\hline Bard Offshore 1 & DE & 400 & 35 \\
\hline Anholt 1 & DK & 400 & 49 \\
\hline Duddon Sands & UK & 389 & 46 \\
\hline Arkona & DE & 385 & 53 \\
\hline Norther & BE & 370 & 38 \\
\hline Galloper & UK & 353 & 45 \\
\hline Baltic 1\&2 & DE & 336 & 46 \\
\hline Nordsee One & DE & 331 & 32 \\
\hline Gode Wind I & DE & 330 & 42 \\
\hline Sheringham Shoal & UK & 317 & 40 \\
\hline B.Riffgrund I & DE & 312 & 39 \\
\hline Rentel & BE & 309 & 37 \\
\hline Amrumbank West & DE & 302 & 44 \\
\hline Thanet & UK & 300 & 33 \\
\hline
\end{tabular}

\begin{tabular}{|l|c|c|c|}
\hline Wind Farm & Country & $\begin{array}{c}\text { Capacity } \\
\text { (MW) }\end{array}$ & C.F. \\
\hline DanTysk & DE & 288 & 50 \\
\hline Sandbank & DE & 288 & 50 \\
\hline Lincs & UK & 270 & 42 \\
\hline Burbo Bank 2 & UK & 254 & 40 \\
\hline Gode Wind II & DE & 252 & 41 \\
\hline Humber Gateway & UK & 219 & 43 \\
\hline Northwind & BE & 216 & 41 \\
\hline Westermost Rough & UK & 210 & 47 \\
\hline Horns Rev II & DK & 209 & 48 \\
\hline Nysted II & DK & 207 & 44 \\
\hline Walney phase 2 & UK & 184 & 46 \\
\hline Walney phase 1 & UK & 184 & 40 \\
\hline Thorntonbank SW & BE & 175 & 36 \\
\hline Robin Rigg & UK & 174 & 35 \\
\hline Gunfleet Sands & UK & 173 & 37 \\
\hline Nysted (Rødsand) I & DK & 166 & 37 \\
\hline Nobelwind & BE & 165 & 43 \\
\hline Belwind & BE & 165 & 38 \\
\hline Horns Rev I & DK & 160 & 41 \\
\hline Thorntonbank NE & BE & 159 & 32 \\
\hline Ormonde & UK & 150 & 38 \\
\hline Nordsee Ost 2 & DE & 144 & 36 \\
\hline Nordsee Ost 1 & DE & 144 & 36 \\
\hline UK:United Kingdom DE:Germany BE:Belgium \\
DK:Denmark & & & \\
\hline
\end{tabular}

\section{CONCLUSION}

This work aims to investigate the feasibility of constructing an offshore wind farm at the Gulf of Edremit, a very high potential site located at the Aegean Sea, $3 \mathrm{~km}$ from the west coastline of Turkey. Detailed analyses are conducted for a 50 - $90 \mathrm{MW}$ capacity offshore wind park by using two different site assessment programs namely, WASP and FUGA. Capacity factors and the corresponding AEP (Annual Energy Production) yields are calculated for 8 different types of turbines with rated powers changing between 2 MW and 3.6 MW.

The wake loses and the energy yields calculated by two different tools are very close. The slight difference can be attributed to the fact that these programs are based on different wake models and assumptions. Considering that air flow characteristics can be different on land and on sea, some additional fine tuning can still be needed in deciding the correct values of the analysis parameters utilized.

Depending on the type of turbine, capacity factors change between 0.43 and 0.46 which can be considered to be quite high and economically feasible for the construction of the proposed offshore wind farm. The turbines to be installed can be decided by comparing either the relative efficiencies (capacity factors) or the total energy production. Since the efficiencies predicted for different models are very close, it is recommended to maximize the energy production by using a high capacity turbine (3.6 MW) resulting in a wind farm with a total capacity of $90 \mathrm{MW}$ and capacity factor of $44.5 \%$. 
Once the efficiencies of the active offshore wind parks located in Europe are considered, it was observed that the total capacity of the farms having a C.F. greater than or equal to $44.5 \%$ is $4,691 \mathrm{MW}$ or $32 \%$ of the total installed offshore wind power. Therefore, it can be concluded that the proposed wind farm will be more efficient than remaining $68 \%$ of the major wind farms located in European Countries. The $90 \mathrm{MW}$ capacity offshore wind farm is calculated to have an average net annual energy yield of $352 \mathrm{GWh}$.

Turbines with larger size and capacity can also be installed in the analyzed region but larger turbines may require some additional technical modifications in the design such as using a different type of foundation. Therefore, they have not been included in this work which is mainly a relative efficiency and capacity factor based comparison made among the turbines which can be installed by using similar construction techniques.

As mentioned earlier, the renewable energy program initiated in 2007 has increased the total wind power capacity from $146 \mathrm{MW}$ in 2007 to 8,056 MW in 2019, but the total capacity is still limited to onshore wind turbine installations only. Although Turkey is surrounded by sea on three sides and has a coastline of 8,300 $\mathrm{km}$, currently there is no offshore wind farm in Turkey. As a case study, this work is expected to contribute to the development of possible future offshore projects by pointing the wind energy potential of one of the most promising sites which can be used for this purpose.

\section{CONFLICTS OF INTEREST}

No conflict of interest was declared by the authors.

\section{REFERENCES}

[1] Global Wind Report-2019. GWEC, Global Wind Energy Council, (2019).

[2] Colmenar-Santos, A., Perera-Perez, J., Borge-Diez, D., Depalacio-Rodríguez, C., "Offshore wind energy: A review of the current status, challenges and future development in Spain", Renewable and Sustainable Energy Reviews, 64: 1-18, (2016).

[3] Rodrigues, S., Bauer, P., Bosman, P.A.N., "Multi-objective optimization of wind farm layoutsComplexity, constraint handling and scalability", Renewable and Sustainable Energy Reviews, 65: 587-609, (2016).

[4] Schallenberg-Rodríguez, J., García Montesdeoca, N., "Spatial planning to estimate the offshore wind energy potential in coastal regions and islands. Practical case: The Canary Islands", Energy, 143: 91-103, (2018).

[5] Chancham, C., Waewsak, J., Gagnon, Y., "Offshore wind resource assessment and wind power plant optimization in the Gulf of Thailand", Energy, 139: 706-731, (2017).

[6] Al-Nassar, W.K., Neelamani, S., Al-Salem, K.A., Al-Dashti, H.A., "Feasibility of offshore wind energy as an alternative source for the state of Kuwait", Energy, 169: 783-796, (2019).

[7] Kim, J.Y., Oh, K.Y., Kim, M.S., Kim, K.Y., "Evaluation and characterization of offshore wind resources with long-term met mast data corrected by wind lidar", Renewable Energy, 41-55, (2019).

[8] Alkhalidi, M.A., Al-Dabbous, S.K., Neelamani, S., Aldashti, H.A., "Wind energy potential at coastal and offshore locations in the state of Kuwait", Renewable Energy, 529-539, (2019).

[9] Oh, K.Y., Nam, W., Ryu, M.S., Kim, J.Y., Epureanu, B.I., "A review of foundations of offshore wind energy convertors: Current status and future perspectives", Renewable and Sustainable Energy Reviews, 88: 16-36, (2018). 
[10] Al-Nassar, W., Alhajraf, S., Al-Enizi, A., Al-Awadhi, L., "Potential wind power generation in the State of Kuwait", Renewable Energy, 30(14): 2149-2161, (2005).

[11] Wang, Y.H., Walter, R.K., White, C., Farr, H., Ruttenberg, B.I., "Assessment of surface wind datasets for estimating offshore wind energy along the Central California Coast", Renewable Energy, 343-353, (2019).

[12] Neelamani, S., Al-Awadi, L., Al-Shatti, F., Al-Khaldi, M., Abdullah, M., Hussain, M., "Extreme wind and gust speed at the territorial waters of Kuwait, Arabian Gulf", Wind Engineering, 38(1): 39-72, (2014).

[13] Kim, J.Y., Oh, K.Y., Kang, K.S., Lee, J.S., "Site selection of offshore wind farms around the Korean Peninsula through economic evaluation", Renewable Energy, 54: 189-195, (2013).

[14] http://www.enerji.gov.tr/en-US/Pages/Electricity. Access date 30.04.2020.

[15] Yazicioglu, H., Tunc, K.M.M., Ozbek, M., Kara, T., "Simulation of electricity generation by marine current turbines at Istanbul Bosphorus Strait”, Energy, 95:41-50, (2016).

[16] Cali, U., Erdogan, N., Kucuksari, S., Argin, M., "Techno-Economic analysis of high potential offshore wind farm locations in Turkey”, Energy Strategy Reviews, 22: 325-336, (2018).

[17] Satir, M., Murphy, F., McDonnell, K., "Feasibility study of an offshore wind farm in the Aegean Sea, Turkey", Renewable and Sustainable Energy Reviews, 81: 2552-2562, (2018).

[18] Kaplan, Y.A., "Overview of wind energy in the world and assessment of current wind energy policies in Turkey", Renewable and Sustainable Energy Reviews, 43: 562-568, (2015).

[19] Ucar, A., Balo, F., "Assessment of wind power potential for turbine installation in coastal areas of Turkey”, Renewable and Sustainable Energy Reviews, 14: 1901-1912, (2010).

[20] Argin, M., Yerci, V., "Offshore wind power potential of the Black Sea region in Turkey", International Journal of Green Energy, 14: 811-818, (2017).

[21] http://www.yegm.gov.tr/YEKrepa/REPA-duyuru_01.html. Access date 30.04.2020.

[22] https://www.google.com/earth/. Access date 30.04.2020.

[23] https://www.gebco.net/. Access date 30.04.2020.

[24] Troen, I., Lundtang, Petersen E., "European Wind Atlas”, Risø National Laboratory, Roskilde, (1989).

[25] Hahmann, A.N., Lennard, C., Badger, J., Vincent, C.L., Kelly, M.C., Volker, P.J.H., Argent, B., Refslund, J., "Mesoscale modeling for the Wind Atlas of South Africa (WASA) project", DTU Wind Energy. DTU Wind Energy E, No. 0050 (updated), (2015).

[26] Lundtang Petersen, E., Mortensen, N.G., Landberg, L., Højstrup, J., Frank, H.P., "Wind Power Meteorology”, Risø National Laboratory. Risø-I No. 1206(EN), Roskilde, (1997).

[27] Mortensen, N.G., Landberg, L., Troen, I., Lundtang Petersen, E., Rathmann, O., Nielsen, M., "Wind Atlas Analysis and Application program (WAsP): Vol. 3: Utility programs", (4th Ed.) Risø National Laboratory. Risø-I, No. 666(v.3)(EN), Roskilde, (1999). 
[28] Ott, S., Berg, J., Nielsen, M., "Linearised CFD Models for Wakes", Danmarks Tekniske Universitet, Risø National Laboratory. Risoe-R, No. 1772(EN), Roskilde, (2011).

[29] https://gmao.gsfc.nasa.gov/reanalysis/MERRA/. Access date 30.04.2020.

[30] Gumbel, E.J., Mustafi, C.K., "Some Analytical Properties of Bivariate Extremal Distributions", Journal of the American Statistical Association, 62(318): 569-588, (1967).

[31] https://deepresource.wordpress.com/2018/09/01/offshore-wind-capacity-factors/. Access date 30.04.2020. 